\title{
Effect of N-3 Pufa Rich Sources on Post Hatch Growth Performance of Japanese Quail
}

\author{
G. Raj Manohar* \\ College of Poultry Production and Management, Tamil Nadu Veterinary and Animal Sciences \\ University, Hosur, India \\ *Corresponding author
}

\begin{abstract}
A B S T R A C T
A study was conducted to assess the Post hatch growth performance in Japanese quail fed with Omega-3 PUFA rich sources like fish oil and linseed oil, independently and simultaneously at 2 and 4 per cent levels in quail ration. The biological experiment was carried out by using, five hundred and twenty five day old straight-run Japanese quail chicks up to 5 weeks of age for post hatch growth performance studies. Individual body weight and total feed consumption in each replicate group were recorded at weekly intervals to calculate the weight gain and feed efficiency. The mean body weight gain at the end of fifth week ranged between $204.53 \mathrm{~g}$ and $223.78 \mathrm{~g}$ and birds fed basal diet with 4 per cent fish oil $\left(\mathrm{T}_{4}\right)$ had significantly higher body weight gain $(223.78 \mathrm{~g})$ as compared to Japanese quail fed basal diet alone $\left(\mathrm{T}_{1}\right)(210.66 \mathrm{~g})$. However, the Japanese quail fed 4 per cent linseed oil (204.53 g) had the lowest body weight gain at fifth week of age between the treatment groups. Japanese quail grouped under 4 per cent fish oil had better feed efficiency (2.77) when compared to control group alone. Meanwhile, the birds grouped under 4 per cent linseed oil recorded poor feed efficiency (3.14) between the treatment groups. It is concluded that inclusion of n-3 PUFA rich fish oil and linseed oil sources at graded levels independently and simultaneously in Japanese quail feed revealed that birds fed diets enriched with fish oil at four and two per cent levels had significant $(\mathrm{P}<0.01)$ effect on body weight gain and feed efficiency with non-significant variation observed in cumulative feed consumption.
\end{abstract}

Keywords

Japanese quailOmega-3 PUFAs Designer foodsPost hatch Growth performance

\section{Introduction}

Japanese quail (Coturnix coturnix japonica) is the smallest domesticated avian species grown for meat and egg production. Commercial Japanese quail farming has created a huge impact in recent years and is being increasingly gaining momentum in Asian countries especially India. Its distinct characteristics include fast growth, shorter generation interval, simple rearing procedure, its ability to withstand wider range of climatic and farm conditions. Small size and rapid growth in Japanese quail has enabled enterprises to be established with low capital outlay, and to start generating income early. Keeping this in view, the present study is aimed to study the effect of n-3 (or) Omega-3 
PUFA rich oil sources on Post hatch growth performance of Japanese quail.

\section{Materials and Methods}

The biological experiment was carried out by using five hundred and twenty five day old straight-run Japanese quail chicks reared up to 5 weeks of age for Post hatch growth performance studies. The birds were wing banded, weighed individually and randomly allotted into following seven treatment groups with three replicates having 25 chicks in each replicate.

\begin{tabular}{|c|c|}
\hline Treatment groups & Experimental feed for Japanese quail \\
\hline$T_{1}$ & Control (without oils) \\
\hline$T_{2}$ & $2 \%$ Fish oil \\
\hline$T_{3}$ & $2 \%$ Linseed oil \\
\hline$T_{4}$ & $4 \%$ Fish oil \\
\hline$T_{5}$ & $4 \%$ Linseed oil \\
\hline$T_{6}$ & $2 \%(1 \%$ Fish oil $+1 \%$ Linseed oil $)$ \\
\hline$T_{7}$ & $4 \%(2 \%$ Fish oil $+2 \%$ Linseed oil $)$ \\
\hline
\end{tabular}

Seven experimental Japanese quail basal diets were formulated as per the standards prescribed by Shrivastav and Panda (1999) on isocaloric and isonitrogenous basis. The birds were reared under cage system of management with standard management practices throughout the experimental period. The birds were fed with experimental diet ad libitum and had free access to wholesome water throughout the experimental period except for the variation of polyunsaturated fatty acid (PUFA) rich sources used in ration. The newly hatched Japanese quail chicks obtained from the respective breeder groups were reared up to 5 weeks of age for posthatch growth performance studies under cage system of management to know the effect of PUFA rich sources in parent stock.

All the birds were fed with isonitrogenous and isocaloric Japanese quail diets with fish and linseed oils and were randomly allotted to seven treatment groups by referring to random number table. Birds allotted in each treatment were further distributed to three replicates in equal number. The data on body weight gain, feed consumption, feed efficiency as well as livability were worked out.
Individual body weight and total feed consumption in each replicate group were recorded at weekly intervals to calculate the weight gain and feed efficiency. The data collected were subjected to statistical analyses as per Snedecor and Cochran (1989).

\section{Results and Discussion}

\section{Body weight gain}

The mean body weight gain of post-hatch performance of Japanese quail from first to fifth week of age as influenced by supplementing PUFA rich oil sources independently and simultaneously in feed to the chicks is presented in Table 1.

The mean body weight gain at the end of fifth week ranged between $204.53 \mathrm{~g}$ and $223.78 \mathrm{~g}$ and birds fed basal diet with 4 per cent fish oil $\left(\mathrm{T}_{4}\right)$ had significantly higher body weight gain (223.78 g) as compared to Japanese quail fed basal diet alone $\left(\mathrm{T}_{1}\right)$ (210.66 g). However, the Japanese quail fed 4 per cent linseed oil $(204.53 \mathrm{~g})$ had the lowest body weight gain at fifth week of age between the treatment groups. Statistical analysis revealed no significant influence on body weight gain 
during first and second week, highly significant $(\mathrm{P}<0.01)$ difference during third, fourth and fifth week was observed.

The analysis of data revealed non-significant differences in body weight gain of post-hatch Japanese quail performance during first and second weeks of age while highly significant $(\mathrm{P}<0.01)$ differences were observed from third to fifth week of age among the treatment groups. The body weight of post hatch Japanese quail fed diet with 4 per cent fish oil (T4) had significantly higher body weight gain as compared to Japanese quail fed basal diet alone (T1).

Aranibar et al., (2001) studied the effects of post hatch fasting and type and level of initial dietary fat on production traits in broilers and concluded that daily body weight gain from hatching to 42 days of age was not significantly affected by duration of starvation, or by the type or by inclusion of 3 or 8 per cent of sunflower oil, fish oil or butter in the diet which is in partial agreement with the results of this study.

Table.1 Mean body weight gain (g) ( \pm S.E.) of Post-hatch Japanese quail performance as influenced by feeding PUFA rich oil sources from 1 to 5 weeks of age

\begin{tabular}{|c|c|c|c|c|c|}
\hline Treatment g & I - We & II - Week & III - Week & IV - Week & V - Week \\
\hline $\mathbf{T}_{1}$ - Control & $25.20 \pm 0.61$ & $67.77 \pm 1.93$ & $119.09^{\mathrm{A}} \pm 4.31$ & $169.24^{\mathrm{A}} \pm 3.44$ & $210.66^{\mathrm{AB}} \pm 3.24$ \\
\hline $\begin{array}{l}\mathrm{T}_{2-}-2 \% \text { Fish oil } \\
\text { (FO) }\end{array}$ & $24.82 \pm 0.64$ & $71.71 \pm 1.19$ & $125.41^{\mathrm{AB}} \pm 2.10$ & $179.87^{\mathrm{B}} \pm 2.56$ & $220.71^{B C} \pm 3.41$ \\
\hline $\begin{array}{l}\mathrm{T}_{3-}-2 \% \text { Linseed oi } \\
\text { (LO) }\end{array}$ & $25.64 \pm 0.50$ & $72.18 \pm 1.03$ & $128.36^{\mathrm{BC}} \pm 1.79$ & $174.10^{\mathrm{AB}} \pm 1.94$ & \\
\hline $\mathrm{T}_{4}-4 \%$ Fish oil & $5.98 \pm 0.53$ & $72.41 \pm 1.10$ & $134.29^{C} \pm 2.29$ & $180.01^{\mathrm{B}} \pm 3.36$ & $223.78^{C} \pm 3.90$ \\
\hline & $27.20 \pm 0.56$ & $71.76 \pm 1.37$ & $121.67^{\mathrm{AB}} \pm 2.15$ & $167.83^{\mathrm{A}} \pm 2.61$ & $204.53^{A} \pm 2.77$ \\
\hline $\mathrm{T}_{6}-2 \%$ & $25.37 \pm 0.62$ & $72.92 \pm 1.54$ & $127.77^{\mathrm{B}} \pm 3.86$ & $178.43^{\mathrm{B}} \pm 2.95$ & $218.03^{B C} \pm 3.57$ \\
\hline $\mathrm{T}_{7 .} 4 \%(\mathrm{FO}+\mathrm{LO})$ & $24.62 \pm 0.69$ & $70.89 \pm 1.46$ & $130.08^{\mathrm{BC}} \pm 2.23$ & $178.26^{\mathrm{B}} \pm 3.06$ & $215.52^{\mathrm{BC}} \pm 3.67$ \\
\hline
\end{tabular}

Value within each cell is a mean of 45 observations

${ }^{A-C}$ Mean values not sharing a common superscript columnwise differ significantly. $(\mathrm{P}<0.01)$

Table.2 Mean cumulative feed consumption (g) ( \pm S.E.) of Post-hatch Japanese quail performance as influenced by feeding PUFA rich oil sources from 1 to 5 weeks of age

\begin{tabular}{|l|c|c|c|c|c|}
\hline \multicolumn{1}{|c|}{ Treatment groups } & I - Week & II - Week & III - Week & IV - Week & V - Week \\
\hline $\mathbf{T}_{\mathbf{1}}$ - Control & $46.29 \pm 0.98$ & $137.58 \pm 2.88$ & $278.01 \pm 0.37$ & $439.26 \pm 7.58$ & $\mathbf{6 3 6 . 6 1} \pm \mathbf{9 . 5 8}$ \\
\hline $\mathbf{T}_{\mathbf{2}} \mathbf{2 \%}$ Fish oil (FO) & $41.27 \pm 2.71$ & $132.11 \pm 5.72$ & $267.58 \pm 5.75$ & $427.09 \pm 8.27$ & $\mathbf{6 1 9 . 8 8} \pm \mathbf{9 . 7 2}$ \\
\hline $\begin{array}{l}\mathbf{T}_{\mathbf{3}} \mathbf{2 \%} \text { Linseed oil } \\
(\mathbf{L O})\end{array}$ & $44.56 \pm 4.79$ & $137.00 \pm 9.02$ & $275.32 \pm 7.99$ & $435.73 \pm 7.88$ & $\mathbf{6 3 5 . 6 7} \pm \mathbf{8 . 8 3}$ \\
\hline $\mathbf{T}_{\mathbf{4}} \mathbf{4 \%}$ Fish oil & $39.78 \pm 1.60$ & $130.69 \pm 2.07$ & $267.51 \pm 3.32$ & $423.53 \pm 7.89$ & $\mathbf{6 2 0 . 2 6} \pm \mathbf{8 . 1 5}$ \\
\hline $\mathbf{T}_{\mathbf{5}} \mathbf{4 \%}$ Linseed oil & $45.89 \pm 1.39$ & $140.31 \pm 2.34$ & $276.74 \pm 0.41$ & $441.00 \pm 1.77$ & $\mathbf{6 4 1 . 4 3} \pm \mathbf{1 . 9 1}$ \\
\hline $\mathbf{T}_{\mathbf{6}} \mathbf{2}$ \% (FO +LO) & $46.00 \pm 2.69$ & $140.07 \pm 4.68$ & $276.13 \pm 5.24$ & $434.52 \pm 7.78$ & $\mathbf{6 2 8 . 1 4} \pm \mathbf{8 . 1 6}$ \\
\hline $\mathbf{T}_{\mathbf{7 -}} \mathbf{4}$ \% (FO +LO) & $\mathbf{4 1 . 1 8} \pm \mathbf{0 . 6 6}$ & $\mathbf{1 3 0 . 8 9} \pm \mathbf{1 . 4 2}$ & $\mathbf{2 6 7 . 1 4} \pm \mathbf{3 . 3 3}$ & $\mathbf{4 3 1 . 6 6} \pm \mathbf{5 . 6 8}$ & $\mathbf{6 2 5 . 6 3} \pm \mathbf{6 . 1 9}$ \\
\hline
\end{tabular}

Value within each cell is a mean of three observations 
Table.3 Mean cumulative feed efficiency $( \pm$ S.E.) of post-hatch Japanese quail performance as influenced by feeding PUFA RICH oil sources from 1 to 5 weeks of age

\begin{tabular}{|c|c|c|c|c|c|}
\hline Treatment groups & I - Week & II - Week & III - Week & IV - Week & V - Week \\
\hline $\mathbf{T}_{1}$ - Control & $1.84 \pm 0.05$ & $2.08 \pm 0.27$ & $2.45 \pm 0.41$ & $2.61^{b c} \pm 0.14$ & $3.03^{\mathrm{BC}} \pm 0.07$ \\
\hline $\mathrm{T}_{2-} 2 \%$ Fish oil (FO) & $1.66 \pm 0.08$ & $1.84 \pm 0.07$ & $2.13 \pm 0.06$ & $2.37^{\mathrm{a}} \pm 0.04$ & $2.81^{A} \pm 0.02$ \\
\hline $\mathrm{T}_{3}-2 \%$ Linseed oil (LO) & $1.74 \pm 0.18$ & $1.90 \pm 0.13$ & $2.14 \pm 0.05$ & $2.50^{\mathrm{abc}} \pm 0.03$ & $3.01^{\mathrm{BC}} \pm 0.03$ \\
\hline $\mathrm{T}_{4}-4 \%$ Fish oil & $1.53 \pm 0.04$ & $1.81 \pm 0.01$ & $1.99 \pm 0.03$ & $2.35^{\mathrm{a}} \pm 0.03$ & $2.77^{\mathrm{A}} \pm \mathbf{0 . 0 1}$ \\
\hline$T_{5^{-}} 4 \%$ Linseed oil & $1.69 \pm 0.08$ & $1.96 \pm 0.05$ & $2.28 \pm 0.07$ & $2.63^{c} \pm 0.08$ & $3.14^{\mathrm{C}} \pm 0.04$ \\
\hline $\mathrm{T}_{6}-2 \%(\mathrm{FO}+\mathrm{LO})$ & $1.83 \pm 0.19$ & $1.92 \pm 0.10$ & $2.16 \pm 0.03$ & $2.44^{\mathrm{abc}} \pm 0.01$ & $2.88^{\mathrm{AB}} \pm 0.04$ \\
\hline $\mathrm{T}_{7 .} 4 \%(\mathrm{FO}+\mathrm{LO})$ & $1.68 \pm 0.10$ & $1.85 \pm 0.06$ & $2.05 \pm 0.02$ & $2.42^{\mathrm{ab}} \pm 0.01$ & $2.90^{\mathrm{AB}} \pm 0.04$ \\
\hline
\end{tabular}

Value within each cell is a mean of three observations

${ }^{A-C}$ Mean values not sharing a common superscript column wise differ significantly $(P<0.01)$

${ }^{a b c}$ Mean values not sharing a common superscript column wise differ significantly $(P<0.05)$

\section{Cumulative feed consumption}

The mean cumulative feed consumption on post-hatch performance of Japanese quail from first to fifth week of age is presented in Table 2. The mean cumulative feed consumption at the end of fifth week of age ranged between $619.88 \mathrm{~g}$ and $641.43 \mathrm{~g}$. Japanese quail fed basal diet with 4 per cent linseed oil $\left(\mathrm{T}_{5}\right)$ consumed more feed (641.43 g) when compared to control group (636.61g) alone. However, Japanese quail birds fed with fish oil at 2 per cent level had consumed less feed $(619.88 \mathrm{~g})$ followed in ascending order by the Japanese quail birds grouped under 4 per cent fish oil $\left(\mathrm{T}_{4}\right)(620.26 \mathrm{~g}), 4$ per cent combination of fish and linseed oil $\left(\mathrm{T}_{7}\right)$ $(625.63 \mathrm{~g}), 2$ per cent combination of fish and linseed oils $\left(\mathrm{T}_{6}\right)(628.14 \mathrm{~g})$ and 2 per cent linseed oil group $\left(\mathrm{T}_{3}\right)(635.67 \mathrm{~g})$ as compared to Japanese quail birds consumed the basal diet alone (Control).

Even though there was a numerical variations in feed consumption noticed among the treatment groups, no significant differences were observed throughout the experimental period.

The present study revealed that the inclusion of n-3 PUFA rich oil sources in post-hatch
Japanese quail diet had no significant influence on body weight gain during starter period and cumulative feed consumption throughout the experimental period which is in agreement with the earlier reports of Chanmugham et al., (1992), Saricicek et al., (1997), Newman et al., (2002), Liu et al., (2003), Olomu and Baracos (1991) and An et al., (1995).

The research findings demonstrated that posthatch Japanese quail fed basal diet with 4 per cent linseed oil consumed cumulatively more feed which coincides with the earlier report of Lopez-Ferrer et al., (1999) who stated that increased feed consumption was observed in linseed oil fed groups until five weeks of age. Contrary to the above findings, Crespo and Esteve-Garcia (2001) stated that feed intake of broilers decreased significantly as dietary fat (linseed oil) increased.

\section{Feed efficiency}

The mean feed efficiency on post-hatch performance of Japanese quail up to fifth week of age as influenced by supplementing PUFA rich oil sources independently and simultaneously in feed is presented in Table 3. 
The results of this study revealed that Japanese quail birds grouped under 4 per cent fish oil had better feed efficiency (2.77) when compared to control group alone. Meanwhile, the birds grouped under 4 per cent linseed oil recorded poor feed efficiency (3.14) between the treatment groups.

Statistical analysis revealed no significant differences in feed efficiency until third week of age. However, significant $(\mathrm{P}<0.05)$ and highly significant $(\mathrm{P}<0.01)$ differences were observed during fourth and fifth weeks of age, respectively. On the contrary, Crespo and Esteve-Garcia (2001) reported that feed efficiency was better in birds fed diets with 10 per cent linseed oil because of the higher metabolizable energy content.

\section{Livability}

The results of the present study indicated that the total livability percentages of post-hatch Japanese quail in all groups were 100 due to supplementation of various $\mathrm{n}-3$ PUFA rich sources independently and simultaneously in feed. In general, the present study suggested that supplementation of various n-3 PUFA rich sources in post hatch Japanese quail feed had no deleterious effect on health of the birds and the livability was uniformly superior in all the treatment groups

In conclusion it is noticed from the post-hatch growth performance studies that there is a highly significant $(\mathrm{P}<0.01)$ increase in body weight gain $(223.78 \mathrm{~g})$ and feed efficiency (2.77-3.14) during $\mathrm{V}$ week in Japanese quail fed diets enriched with fish oil at four and two per cent levels. However, inclusion of n-3 PUFA rich fish oil and linseed oil sources at graded levels independently and simultaneously in Japanese quail feed revealed non-significant variation in cumulative feed consumption and livability

\section{References}

An, B.K., Tanaka, K. and Ohtani, S.1995. Effects of various n-3/n-6 fatty acid ratios in diet on lipid metabolism in growing chicks. Anim. Sci. Technol., 66(10): 830-840 (Poult.Abstr., 1996, 22(5): 1235).

Aranibar, M. J., Gracia, M. I. and Mateos, G. G. 2001. Effects of post-hatching fasting and type and level of initial dietary fat on production traits in broilers. In: IX Jornadassobre Production Animal, 25-27 April 2001, Zaragoza, Spain, ( Poult. Abstr., 2002, 28(9): 2882).

Chanmugam, P., Boudreau, M., Boutte, T., Park, R.S., Hebert, J., Berrio, L. and Hwang, D.H. 1992. Incorporation of different types of n-3 fatty acids into tissue lipids of poultry. Poult. Sci., 71 : 516-521.

Crespo, N and Esteve-Garcia, E. 2001. Dietary fatty acid profile modifies abdominal fat deposition in broiler chickens. Poult. Sci., 80 : 71-78.

Liu,D., Veit, H.P., Wilson, J.H. and Denbow, D.M. 2003. Long-term supplementation of various dietary lipids alters bone mineral content, mechanical properties and histological characteristics of Japanese quail. Poult.Sci., 82: 831-839.

Lopez-Ferrer,S., Baucells, M.D., Barroeta, A.C. and Grashorn, M.A. 1999. n-3 enrichment of chicken meat using fish oil: Alternative substitution with rapeseed and linseed oils. Poult.Sci., 78: $356-365$.

Newman. R. E., Bryden, W. L., Fleck, E., Ashes, J. R., Buttemer, W.A. Storlien, L. H. and Downing, J. A. 2002. Dietary n-3 and n-6 fatty acids alter avian metabolism: Metabolism and abdominal fat deposition. Br.J.Nutr., 88(1) : 11-18 (Poult.Abstr., 2002, 28(10) :3196).

Olomu, J.M. and Baracos, V.E. 1991. 
Influence of dietary flax seed oil on the performance, muscle protein deposition, and fatty acid composition of broiler chicks. Poult.Sci., 70 : 1403 - 1411.

Saricicek, B.Z., Ocak, N. and Garipoglu, A.V. 1997. A study on utilizing fish oil in broiler diets. Ziraat Fakultesi Dergisi, 12(1):33-42 (Poult.Abstr., 1998, 24(7):
2068).

Shrivastav, A.K. and Panda, B. 1999. A review of quail nutrition research in India. World's Poult.Sci.J., 55 : 73-81.

Snedecor, G.W. and Cochran, W.G. 1989. Statistical methods. $8^{\text {th }}$ ed. Iowa State University Press / Ames, Iowa - 50010.

\section{How to cite this article:}

Raj Manohar, G. 2020. Effect of N-3 Pufa Rich Sources on Post Hatch Growth Performance of Japanese Quail Int.J.Curr.Microbiol.App.Sci. 9(10): 3870-3875.

doi: https://doi.org/10.20546/ijcmas.2020.910.445 